\title{
Nutrition labels on pre-packaged foods: a systematic review
}

\author{
Sarah Campos, Juliana Doxey and David Hammond* \\ Department of Health Studies and Gerontology, University of Waterloo, 200 University Avenue West, Waterloo, \\ Ontario N2L 3G1, Canada
}

Submitted 18 March 2010: Accepted 20 October 2010: First published online 18 January 2011

\begin{abstract}
Objective: To review research on consumer use and understanding of nutrition labels, as well as the impact of labelling on dietary habits.

Design: A systematic review was conducted by searching electronic databases. Relevant articles were screened by two reviewers and included if they met inclusion criteria, including eight methodological criteria. A total of 120 articles were included in the review, including cross-sectional surveys ( $n$ 96), experimental designs ( $n$ 17), 'natural experiments' ( $n$ 7) and longitudinal populationbased surveys ( $n$ 2).

Setting: Articles covered seven jurisdictions: USA ( $n$ 88), Europe ( $n 12)$, Canada $(n 9)$, Australia and New Zealand ( $n$ 4), Norway $(n 2)$, Thailand $(n 1)$ and Trinidad $(n 1)$. Subjects: Participants were from a wide range of age groups, socio-economic strata and geographical regions.

Results: Nutrition labels on pre-packaged foods are among the most prominent sources of nutrition information. Nutrition labels are perceived as a highly credible source of information and many consumers use nutrition labels to guide their selection of food products. Evidence also shows a consistent link between the use of nutrition labels and healthier diets. However, the use of labels varies considerably across subgroups, with lower use among children, adolescents and older adults who are obese. Research also highlights challenges in terms of consumer understanding and appropriate use of labelling information.

Conclusions: Nutrition labels on pre-packaged foods are a cost-effective populationlevel intervention with unparalleled reach. However, to capitalize on their potential, governments will need to explore new formats and different types of information content to ensure that nutrition information is accessible and understandable.
\end{abstract}

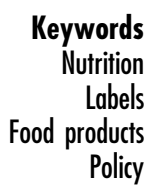

The prevalence of overweight and obesity is increasing at an alarming rate ${ }^{(1,2)}$. Globally, approximately 1.6 billion adults are overweight and over 400 million are obese ${ }^{(2)}$. Although obesity is more common in high-income countries, increases in obesity have occurred in many low- and middle-income countries, particularly among urban populations ${ }^{(2)}$. The increasing prevalence of overweight and obesity places a considerable burden on public health, including increases in CVD, diabetes, arthritis, sleep and breathing disorders, depression, as well as functional limitations ${ }^{(3)}$. Diet is also estimated to account for approximately $30 \%$ of cancers in industrialized countries, making it the second largest modifiable risk factor after cigarette smoking ${ }^{(4)}$. The economic burden of overweight and obesity is considerable, with direct health-care costs in the billions for most Western countries $^{(5)}$.

Nutrition labelling on food products has emerged as a prominent policy tool for promoting healthy eating ${ }^{(6)}$. As a health education intervention, mandatory nutrition labels have broad reach and are present at the point of purchase, as well as when food is prepared or consumed $^{(7)}$. The display of nutritional information on pre-packaged foods is mandatory in most high-income countries. In the USA, the Nutrition Labelling and Education Act of 1990 mandates that pre-packaged foods carry a nutrition label, with exceptions for foods intended for immediate consumption ${ }^{(8)}$. In Canada, mandatory nutrition labelling was first implemented on pre-packaged foods in December 2005 and became mandatory on virtually all pre-packaged foods in $2007^{(8-10)}$. Nutrition labelling on pre-packaged foods remains voluntary in the European Union, except in the case of health claims, although mandatory regulations are under development ${ }^{(11)}$ (see Fig. 1 for examples of nutrition labels in the USA, Canada, Australia and the UK).

There is a large and growing evidence base on the impact of nutritional labels, including six literature reviews between 1991 and $2007^{(6,12-16)}$. The most recent reviews have focused on specific geographical areas, including European 
Canada

Nutrition facts/Valeur nutritive
Serving $11 / 4$ cup $(30 \mathrm{~g}) /$ Portion de $1 \frac{1}{4}$ tasse $(30 \mathrm{~g})$

Amount per serving Cereal

Teneur par portion

Calories / Calories

\begin{tabular}{lcr} 
& $\%$ Daily Value / $\%$ valeur quotidienne \\
\hline Fat / Lipides $0 \mathrm{~g} \dagger$ & $0 \%$ & $4 \%$ \\
\hline Sa & & $0 \%$
\end{tabular}

Saturates/saturés $0 \mathrm{~g} \quad 0 \%$

+ Trans / trans $0 \mathrm{~g}$

Cholesterol / Cholestérol $0 \mathrm{mg} \quad 0 \% \quad 3 \%$

\begin{tabular}{lll}
\hline Sodium / Sodium $220 \mathrm{mg}$ & $9 \%$ & $12 \%$ \\
\hline Polass
\end{tabular}

Potassium / Potassium $30 \mathrm{mg} \quad 1 \%$

\begin{tabular}{lll}
\hline Carbohydrate / Glucides $26 \mathrm{~g}$ & $9 \%$ & $11 \%$ \\
\hline
\end{tabular}

Fibre / Fibres $1 \mathrm{~g} \quad 4 \% \quad 4 \%$

Sugars / Sucres $2 \mathrm{~g}$

Starch / Amidon $23 \mathrm{~g}$

Protein / Protéines $2 \mathrm{~g}$

\begin{tabular}{lll}
\hline Vitamin A / Vitamine A & $0 \%$ & $8 \%$ \\
\hline
\end{tabular}

\begin{tabular}{lll}
\hline Vitamin C / Vitamine C & $0 \%$ & $0 \%$ \\
\hline Calcium / Calcium
\end{tabular}

\begin{tabular}{lrr}
\hline Calcium / Calcium & $0 \%$ & $15 \%$ \\
\hline
\end{tabular}

\begin{tabular}{lll}
\hline Iron / Fer & $30 \%$ & $30 \%$ \\
\hline
\end{tabular}

\begin{tabular}{lrr}
\hline Vitamin D / Vitamine D & $0 \%$ & $25 \%$ \\
\hline Thiamin / Thiamine & $45 \%$ & $50 \%$ \\
\hline
\end{tabular}

Riboflavin / Riboflavine $\quad 50 \% \quad 60 \%$

\begin{tabular}{lrr}
\hline Niacin / Niacine & $8 \%$ & $15 \%$ \\
\hline
\end{tabular}

Vitamin $\mathrm{B}_{6} /$ VItamine $\mathrm{B}_{6} \quad 10 \% \quad 15 \%$

\begin{tabular}{lll}
\hline Floate / Folate & $8 \%$ & $10 \%$ \\
\hline Vitamin $B$ / & $0 \%$ & $25 \%$ \\
\hline
\end{tabular}

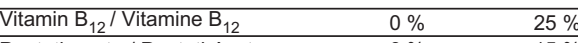

\begin{tabular}{lll}
\hline Pantothenate / Pantothénate & $6 \%$ & $15 \%$ \\
\hline Phosphorus / Phosphore & $2 \%$ & $10 \%$ \\
\hline
\end{tabular}

\begin{tabular}{lll}
\hline Magnesium / Magnésium & $0 \%$ & $8 \%$
\end{tabular}

Zinc/Zinc

† Amount in cereal / Dans les céréales.

NGREDIENTS. FLAKED MILLED CORN SUGARIGUCOSEFRUCTOSE MALT ICORNFLOUR, MALTED BARLEY) SALT NATURAL, COLOUR, VITAMINS (THIAMIN HYDROCHLORIDE) MALTED BARLEY), SALT, NATURAL COLOUR, VITAMINS (THIAMIN HYDROCHLORIDE,
NIACINAMIDE, PYRIDOINE HYDROCHLORIDE, FOLIC ACID, d-CALCIUM PANTOTHENATE), IRON, BHT ADDED TO PACKAGE MATERIAL TO MAINTAIN PRODUCT FRESHNESS CONTANSTRACES OF SOYBEANS. MT

INGREDIENTS : MAIIS MOULU EN FLOCONS, SUCRE/GLUCOSE-FRUCTOSE, MALT (FARINE THIAMINE, NIACINAMIDE, CHLORHYDRATE DE PYRIDOXINE, ACIDE FOLLUUE, d-PANTOTHÉNATE DE CALCIUM), FER, POUR CONSERVER LAFRAICHEUR DU PRODUIT, DU BHT A ÉTÉ AJOUTÉ AU MATERRIEL D'EMBALLAGE, CONTENT DES TRACES DE SOYA.

Australia

\section{NUTRITION INFORMATION}

Servings per package: 3

Serving size: $150 \mathrm{~g}$

\begin{tabular}{|ccc|}
\hline & $\begin{array}{c}\text { Quantity } \\
\text { per serving }\end{array}$ & $\begin{array}{c}\text { Quantity } \\
\text { per } 100 \mathrm{~g}\end{array}$ \\
Energy & $608 \mathrm{~kJ}$ & $405 \mathrm{~kJ}$ \\
Protein & $4.2 \mathrm{~g}$ & $2.8 \mathrm{~g}$ \\
Fat, total & $7.4 \mathrm{~g}$ & $4.9 \mathrm{~g}$ \\
$\quad$ - saturated & $4.5 \mathrm{~g}$ & $3.0 \mathrm{~g}$ \\
Carbohydrate, total & $18.6 \mathrm{~g}$ & $12.4 \mathrm{~g}$ \\
$\quad$ - sugars & $18.6 \mathrm{~g}$ & $12.4 \mathrm{~g}$ \\
Sodium & $90 \mathrm{mg}$ & $60 \mathrm{mg}$ \\
Calcium & 300 mg (38\%)* & $200 \mathrm{mg}$ \\
* Percentage of recommended dietry intake \\
\hline Ingredients: Whole milk, concentrated skim milk \\
sugar, strawberries (9\%), gelatine, \\
culture, thickener (1442). \\
\hline \multicolumn{2}{c}{} \\
\hline
\end{tabular}

USA

\begin{tabular}{|c|c|c|c|}
\hline \multicolumn{4}{|c|}{ Nutrition facts } \\
\hline \multicolumn{4}{|c|}{$\begin{array}{l}\text { Serving size } 1 / 2 \text { cup dry ( } 40 \mathrm{~g} \text { ) } \\
\text { Servings per container: } 13\end{array}$} \\
\hline \multicolumn{4}{|l|}{ Amount per serving } \\
\hline \multirow[t]{2}{*}{ Calories 150} & & \multicolumn{2}{|c|}{ Calories from Fat 25} \\
\hline & & \multicolumn{2}{|c|}{$\%$ Daily value* } \\
\hline \multicolumn{2}{|l|}{ Total Fat $3 \mathrm{~g}$} & & $4 \%$ \\
\hline \multicolumn{2}{|l|}{ Saturated Fat $0.5 \mathrm{~g}$} & & $2 \%$ \\
\hline \multicolumn{2}{|l|}{ Trans Fat $0 \mathrm{~g}$} & & $0 \%$ \\
\hline \multicolumn{2}{|l|}{ Cholesterol $0 \mathrm{mg}$} & & $0 \%$ \\
\hline \multicolumn{2}{|l|}{ Sodium $0 \mathrm{mg}$} & & $0 \%$ \\
\hline \multicolumn{2}{|c|}{ Total Carbohydrate $27 \mathrm{~g}$} & & $9 \%$ \\
\hline \multicolumn{2}{|l|}{ Dietary Fiber $4 \mathrm{~g}$} & & $15 \%$ \\
\hline \multicolumn{4}{|l|}{ Sugars $1 \mathrm{~g}$} \\
\hline \multicolumn{4}{|l|}{ Protein $5 \mathrm{~g}$} \\
\hline \multicolumn{2}{|l|}{ Vitamin A } & & $0 \%$ \\
\hline \multicolumn{2}{|l|}{ Vitamin C } & & $0 \%$ \\
\hline \multicolumn{2}{|l|}{ Calcium } & & $0 \%$ \\
\hline \multicolumn{2}{|l|}{ Iron } & & $10 \%$ \\
\hline \multicolumn{4}{|c|}{$\begin{array}{l}\text { *Percent Daily Values are based on a } 2,000 \text { calorie diet. } \\
\text { Your daily values may be higher or lower depending on } \\
\text { your calorie needs. }\end{array}$} \\
\hline & Calories: & 2,000 & 2,500 \\
\hline \begin{tabular}{|l|} 
Total Fat \\
$\quad$ Sat Fat \\
Cholesterol \\
Sodium \\
Total Carbohydrate \\
Dietary Fiber \\
\end{tabular} & $\begin{array}{l}\text { Less than } \\
\text { Less than } \\
\text { Less than } \\
\text { Less than }\end{array}$ & $\begin{array}{l}65 \mathrm{~g} \\
20 \mathrm{~g} \\
300 \mathrm{mg} \\
2,400 \mathrm{mg} \\
300 \mathrm{~g} \\
25 \mathrm{~g} \\
\end{array}$ & $\begin{array}{l}80 \mathrm{~g} \\
25 \mathrm{~g} \\
300 \mathrm{mg} \\
2,400 \mathrm{mg} \\
375 \mathrm{~g} \\
30 \mathrm{~g} \\
\end{array}$ \\
\hline
\end{tabular}

United Kingdom

\begin{tabular}{|c|c|}
\hline \multicolumn{2}{|c|}{$\begin{array}{l}\text { Nutrition information } \\
\text { Typical values per } 100 \mathrm{~g}\end{array}$} \\
\hline Energy & $245 \mathrm{~kJ} / 58 \mathrm{kca}$ \\
\hline Protein & $4.6 \mathrm{~g}$ \\
\hline Carbohydrate & $7.2 \mathrm{~g}$ \\
\hline of which sugars & $6.5 \mathrm{~g}$ \\
\hline Fat & $1.2 \mathrm{~g}$ \\
\hline of which saturates & $0.2 \mathrm{~g}$ \\
\hline Fibre & $0.2 \mathrm{~g}$ \\
\hline Sodium & $0.1 \mathrm{~g}$ \\
\hline
\end{tabular}

Fig. 1 Examples of nutrition labels on pre-packaged foods

countries $^{(6,15)}$ and Australia and New Zealand ${ }^{(16)}$, with the exception of Cowburn and Stockley, who reviewed literature up to 2002 across a broader geographical area ${ }^{(14)}$.
The findings of these reviews are generally consistent: self-reported use of nutrition labels was found to be prevalent $^{(6,12-16)}$; however, consumers often report 
difficulty in interpreting quantitative information contained in labels ${ }^{(6,13,14,16)}$. Some consumers found different nutrition label formats confusing ${ }^{(15)}$ and generally preferred graphical information to the traditional label ${ }^{(12)}$. Label use was more prevalent among the female population ${ }^{(6,13-15)}$, and could be predicted by health awareness ${ }^{(13)}$, income $e^{(6,14-16)}$ and education level ${ }^{(6,13-16)}$. Finally, one review concluded a positive effect of nutrition labels on $\operatorname{diet}^{(14)}$.

The evidence base and regulatory practice have grown considerably in the 7 years since the last systematic review was conducted. Several countries have implemented mandatory nutrition labelling legislation within this time. Furthermore, many of the previous reviews did not include studies on the link between label use and diet $^{(6)}$. In light of this, the current systematic review aims to examine the existing body of evidence regarding the prevalence of consumer use and understanding of nutrition labels, as well as the impact of nutrition labelling on consumer dietary habits.

\section{Methods}

\section{Inclusion criteria}

The present review was restricted to studies that examined consumer behaviour related to nutrition labels on prepackaged foods, published in English in peer-reviewed journals or research reports completed on behalf of government agencies. Studies were included if they examined the prevalence or determinants of nutrition label use, or if they measured consumer knowledge, understanding, perceptions or format preferences related to nutrition labels. Articles that examined the relationship between nutrition label use or legislation and consumer diet were also included. Articles that only examined health claims, food safety labelling, brand naming, package design or shelf labelling were excluded, as were articles that focused on labelling at the point of purchase.

\section{Search strategy}

Electronic searches were conducted using the following databases: MEDLINE, CSA Illumina Social Sciences Subject Area (covering forty-six databases); Web of Science (including Science Citation Index Expanded (SCI-EXPANDED) - 1900-present); and the Cochrane Library. Additional searches using the reference lists of relevant articles were also conducted.

The initial search generated a total of 23801 citations, of which 1450 titles appeared to meet the inclusion criteria and were reviewed. Of these abstracts, 247 were selected for article retrieval. Following review of the full-text articles, 109 were excluded on the basis that they did not meet the inclusion criteria. The remaining 138 articles were assessed using a data extraction form and were rated on eight methodological criteria (see Table 1).
Table 1 Methodological evaluation criteria for including articles in the review

\begin{tabular}{ll}
\hline Criterion & Possible outcomes \\
\hline $\begin{array}{l}\text { 1. Is the research question well stated? } \\
\text { 2. Is the sample/population identified and } \\
\text { appropriate? }\end{array}$ & Y/N \\
$\begin{array}{l}\text { 3. Are the inclusion/exclusion criteria } \\
\text { described and appropriate? }\end{array}$ & Y/N or N/A \\
$\begin{array}{l}\text { 4. If applicable, is the participation rate } \\
\text { reported and appropriate? }\end{array}$ & Y/N or N/A \\
$\begin{array}{l}\text { 5. Is the same data collection method } \\
\text { used for all respondents? }\end{array}$ & Y/N \\
$\begin{array}{l}\text { 6. Are important baseline variables } \\
\text { measured, valid and reliable? }\end{array}$ & Y/N or N/A \\
$\begin{array}{l}\text { 7. Is the outcome defined and } \\
\text { measurable? }\end{array}$ & Y/N \\
8. Is the statistical analysis appropriate? & Y/N or N/A \\
\hline
\end{tabular}

$\mathrm{Y}$, yes; N, no; N/A, not applicable.

Studies were included in the review if they met all of the eight criteria. This led a total of 120 articles being included in the review.

\section{Results}

The 120 articles selected for review originated from seven jurisdictions: the USA ( $n 87)$, Europe ( $n$ 13), Canada ( $n 9)$, Australia and New Zealand ( $n 4)$, Norway ( $n 2)$, Germany $(n 1)$, Thailand $(n 1)$ and Trinidad $(n 1)$, as well as one study jointly from the UK and the USA, and one including participants from the Netherlands, Germany, France and the UK. Cross-sectional surveys were the most common study design ( $n$ 96), followed by experimental designs ( $n$ 19), 'natural experiments' ( $n$ 7) and longitudinal populationbased surveys ( $n 2$ ). Thirteen of the surveys were based on nationally representative samples and thirty were conducted with individuals who reported being the primary food shopper for their household, or who were approached while shopping for food at the point of purchase.

\section{Prevalence of label use}

Of the 120 studies reviewed, sixty-five reported the frequency with which consumers attended or used nutrition labels on pre-packaged foods ${ }^{(12,15-79)}$. Among studies targeted at the general population, the prevalence of selfreported label use was generally high (e.g. $82 \%$ in New Zealand $^{(64)}, 52 \%$ in Canada ${ }^{(80)}, 47 \%$ in the $\mathrm{EU}^{(69)}$ and $75 \%$ in the $\mathrm{USA}^{(18)}$ ) according to the most recent nationally representative data in each country. Definitions of label 'use' varied across studies, complicating comparisons. For example, several studies defined users as those who cite nutrition labels as a source of nutrition information, rather than other sources such as health-care practitioners ${ }^{(32,43,44)}$. Studies also used different time frames for label use, including 'ever' use $v$. use in the past 1 month $^{(12)}$ or 12 months ${ }^{(53)}$. Overall, these studies indicate that use of nutrition labels among the general population is generally high and typically above $50 \%$. 
Age

A majority of studies found that middle-aged or younger adults were more likely to use nutrition labels than were older individuals $(25,32,37,42,44,47,69-74,80-84)$, with several exceptions ${ }^{(20,30,35,85,86)}$. For example, a large survey of the nutrition perceptions of Americans found that older participants tended to trust nutrition labels as a source of accurate nutrition information to a less extent than younger respondents ${ }^{(44)}$.

Six articles examined the impact of nutrition labels on adolescents ${ }^{(36,54,87-90)}$. Of these, two studies indicated that use of nutritional labels was low among adolescents ${ }^{(54,90)}$. Only one 2004 study of youth at an urban primary care clinic in the USA reported a self-reported prevalence rate: $22 \%$ reported 'always' reading nutrition labels, 57\% 'sometimes' and only $22 \%$ reported 'never' reading them ${ }^{(36)}$. Evaluations of a 2006 US web-based nutrition intervention in adolescents found no improvement in food label use as a result of the intervention ${ }^{(88)}$; however, a similar 2008 study found that web-based interventions increased adolescents' use of labels ${ }^{(89)}$. A single qualitative study examined the use of nutrition labels among children. The majority of US children in grades 3-6 had difficulty using nutrition labels and could not categorize healthy foods on the basis of label ${ }^{(91)}$.

\section{Gender}

Women report using labels significantly more often than men in a majority of studies that include both gen$\operatorname{ders}^{(25,30,33,35,42-44,46,53,59,64,69,70,72-74,76,80,82,85,92,93)}$. Women were also more likely to report that nutrition labels had influenced their food choices ${ }^{(53)}$ and to trust nutrition labels ${ }^{(44)}$. Similar rates of nutrition label use have been documented among women of different levels of income and socio-economic status ${ }^{(34,38,51,55,57)}$. Only four studies reported no significant difference between male and female participants' use of nutrition labels ${ }^{(17,46,94,95)}$.

\section{Income/education}

Most studies have concluded that individuals with lower income are less likely to use nutrition labels ${ }^{(27,62,82,96)}$, with only two studies finding the opposite effect ${ }^{(67,86)}$ and one reporting no significant effect of income ${ }^{(35)}$. Individuals with lower income were also more likely to have lower levels of nutrition knowledge ${ }^{(86,94)}$, which were associated with label non-use $e^{(50,63,80,97)}$. Similar effects have been observed for education levels: individuals with greater education have reported greater use of nutrition labels in most studies ${ }^{(17,30,41,42,44,62,63,67,70,73,76,80,86,92,93,96,97)}$, with only two exceptions ${ }^{(35,94)}$. Seven studies targeting socioeconomically disadvantaged populations reported variable rates of nutrition label use, ranging from $20 \%$ to $74 \%{ }^{(23,38,39,41,51,61,92)}$, although these rates were typically lower than those reported for the general population.

Mixed findings were observed with respect to the effect of employment ${ }^{(67,76,94,96)}$, job satisfaction ${ }^{(69)}$ and rural $v$. urban habitation on label use $\mathrm{e}^{(35,37,62,82,98,99)}$. Only one study of older Americans in 1990 directly compared rural with urban groups, with no significant difference in label use $^{(43)}$. Larger households and those with children were found to more likely use labels ${ }^{(41)}$ and support their mandatory implementation ${ }^{(35,37)}$, as were married couples ${ }^{(27)}$.

\section{Race/ethnicity}

A majority of studies have found that Caucasian participants are significantly more likely to use nutrition labels than are other ethnic groups ${ }^{(21,39,71,100)}$, with one study of African-American adults in North Carolina reporting high levels of use ${ }^{(30)}$. Studies with Latino adults in the USA also reported lower rates of label use ${ }^{(23,51)}$. For example, a study comparing ethnic groups in the USA found that only half of the proportion of Latinos, compared with their African-American and 'white' respondents, had 'ever used' labels ${ }^{(39)}$. Low rates have also been observed among ethnic minorities in New Zealand ${ }^{(61)}$. Racial/ethnic differences have also been observed with respect to the type of information sought from nutrition labels ${ }^{(25)}$. For example, Latinos were found to be more likely to check dietary fibre and $\mathrm{Na}$ information ${ }^{(72)}$.

\section{Health behaviours}

A wide range of studies have examined the association between label use and health practices. Individuals with healthier eating habits report greater use of nutrition labels, either as a result of personal preference ${ }^{(25,30,50,53,80)}$ or because of the requirements of a health-related $\operatorname{diet}^{(25,37,41,43,64,67,68,76,86,96,101)}$. Greater use has also been reported by individuals more concerned with dietary guidelines $^{(32,33,35,41,53,63,86,94,96)}$ and by those who place greater emphasis on the nutritional quality of food while shopping $(35,68,72,94,96,98,102)$. Nutrition and label knowledge $^{(17,31,35,59,80,86,98,103)}$, nutrition education ${ }^{(19,40,41)}$ and knowledge of diet-disease relationships ${ }^{(17,29,31,33,60,71,72,82)}$ or of specific diseases ${ }^{(29)}$ have also been associated with label use, with few exceptions ${ }^{(69,85,94)}$. Weight control $^{(30,33)}$ and diagnosis of a disease ${ }^{(30,41,53,69,79,82,104-106)}$ have also been associated with greater label use.

Grocery shopping habits have been identified as being a strong predictor of nutritional label use. Consumers who spend more time, or report having more time to shop for groceries, were more likely to be label users ${ }^{(86,96,98)}$, and lack of time was consistently reported as a reason for non-use $e^{(17,33,37)}$. Shoppers who placed less emphasis on price $^{(67,86,96)}$ were more likely to use nutrition labels, although one study reported no association ${ }^{(35)}$. The importance of taste was positively related to label use in three studies ${ }^{(35,94,96)}$ and was negatively related by two others $^{(63,86)}$. Meal planning ${ }^{(68,72,86)}$ and grocery spending were other variables related to use ${ }^{(62)}$.

Among health behaviours not directly related to nutrition, using supplements, exercising regularly and not smoking were associated with the use of nutrition labels ${ }^{(19,30,40,68,85)}$. 


\section{Attitudes/perceptions towards nutrition labels}

Many consumers have reported that nutrition labels are an important source of information ${ }^{(22,60,101,107,108)}$, although ingredients and health claims may be perceived as more important ${ }^{(108)}$. Most consumers were willing to use information if it was provided on the label ${ }^{(97)}$, although consumers' beliefs about the healthiness of foods did not necessarily depend on information on the label $^{(109)}$. There was, however, popular support for mandatory labelling in studies, although conflicting findings have been found for consumers' willingness to pay extra for nutrition information ${ }^{(81)}$. Positive attitudes were higher among individuals reporting greater use of labels ${ }^{(56,59,85,108,110)}$; however, negative attitudes were also prevalent in the literature ${ }^{(41,48,111,112)}$. Many consumers believed that serving sizes and health claims were misleading and were sceptical of the compliance of labels to regulatory law ${ }^{(85,113)}$. The credibility of manufacturers' health claims was rated poorly, especially when these claims contradicted nutrition information on the label $^{(59,85,114-116)}$; however, in one case, health claims helped consumers to choose more nutritious products ${ }^{(117)}$. Trust in labels also predicted use ${ }^{(44,60,69)}$, and was greater among younger respondents and among those with higher levels of education ${ }^{(44)}$.

\section{Comprebension and understanding of nutrition labels}

Studies suggest that consumers generally find nutrition labels to be useful ${ }^{(17,54,59,85)}$, although consumers in the $\mathrm{USA}^{(118)}$ and Australia ${ }^{(26)}$ report a desire for simpler presentation of information ${ }^{(26,49,118)}$. In one case, Australian participants requested more detailed information ${ }^{(26)}$. Following the Nutrition Labeling and Education Act in the USA, which implemented a consistent label format in 1993, $80 \%$ of consumers thought that the label was more helpful and the proportions of those seeking more information declined, except with respect to cholesterol information $^{(28)}$.

There is mixed evidence with respect to the ease $\mathrm{e}^{(30,80,93)}$ or difficulty of using nutrition labels ${ }^{(26,107,118)}$. Frequent label use was associated with better understanding in general $^{(69,98,119)}$, with other studies providing mixed results $^{(56,120)}$. Younger participants ${ }^{(53)}$, as well as those with higher education ${ }^{(52,53)}$, income, literacy and numeracy $^{(52)}$, were more likely to report understanding nutrition labels. One longitudinal study found that self-reported awareness of nutrition terms, but not understanding, improved between 1984 and 1994 in Canada ${ }^{(32)}$.

Several studies reported a good understanding of nutrition labels based on consumers' performance on tasks requiring them to retrieve or manipulate information $^{(56,95,121)}$. Understanding was greater in younger ${ }^{(110)}$, female, educated and white participants ${ }^{(121)}$, and was also related to knowledge ${ }^{(95,122,123)}$, perceived understanding ${ }^{(95)}$, attitude towards and motivation to use the nutrition label $^{(95,123)}$, as well as frequent label use ${ }^{(69,98,119)}$. Selfreported understanding is generally high among lowerincome groups ${ }^{(38,41,51)}$; however, with the exception of one sample of individuals eligible for a US food supplementation programme ${ }^{(41)}$, most showed poor performance on items measuring their ability to use the label, especially when calculations were required ${ }^{(38,51)}$. Low perceived self-efficacy in using the label was also reported by women on social assistance ${ }^{(113)}$.

A variety of studies indicate that many consumers have difficulty with the quantitative information presented on labels, especially with respect to recommended daily amounts, per cent daily values, serving sizes or other forms of reference information on the label ${ }^{(17,21,31,52,54,81,85,120,124)}$. This difficulty was common among diabetics ${ }^{(106)}$, chronic kidney disease patients ${ }^{(79)}$, older adults ${ }^{(81,110,125)}$, adolescents ${ }^{(54)}$, infrequent label users ${ }^{(17)}$ and those with less education ${ }^{(81)}$.

Other tasks that were reportedly confusing for consumers included comparisons between products ${ }^{(52)}$, determination of energy per serving and per package ${ }^{(126)}$ and comprehension of E-numbers representing additives $^{(42)}$. For example, $24 \%$ of consumers in Trinidad read nutrition labels without understanding them ${ }^{(46)}$, and this was listed as a reason for non-use among many groups of consumers $^{(37,46,93,125)}$. Several studies conducted among females in the USA and UK have also provided mixed evidence, showing that most participants could locate nutrition information, but had difficulties with per cent daily value and information on food claims ${ }^{(34,55,57)}$. Frequent label reading, better education, better selfassessments of diet quality, health status and nutrition knowledge were related to these skills ${ }^{(55)}$. Educational interventions targeting label knowledge and understanding have generally shown positive results in a range of sub-populations ${ }^{(21,22,54,125,127,128)}$, including among low-income and literacy groups ${ }^{(92)}$.

\section{Label format and content}

Compared with 'traditional' nutrition labels with quantitative information on nutrient content, several studies have reported greater effectiveness for labels using graphics and symbols ${ }^{(129-131)}$, adjective labels ${ }^{(132)}$ and labels with minimal numerical content ${ }^{(76)}$. For example, information accompanied by graphics helped consumers to better apply reference information, especially consumers who had not seen labels before ${ }^{(61)}$. The use of well-recognized health symbols ${ }^{(7,106)}$ and 'traffic lights' may be particularly effective $^{(64,133,134)}$. For example, traffic light symbols which typically display green, amber or red labels to indicate whether foods contain low, medium or high amounts of contents such as fat, saturated fat, sugars - have been found to increase consumer ability to identify healthier food options and consumer attention in general ${ }^{(133,135,136)}$.

Research also suggests that placing nutrition information on the front of packages is more effective than information positioned on the side or back of packages ${ }^{(15,87,137)}$. 
Front-of-pack (FOP) labels may disproportionately benefit those with low-nutrition education and knowledge of nutrition labels ${ }^{(15)}$. For example, in a 2009 study conducted in Australia, consumers supported the idea of FOP labelling, especially when it is consistent across products and manufacturers ${ }^{(134)}$. Simple energy information on the FOP was also well received in a 2007 study conducted in Germany, The Netherlands, France and the $\mathrm{UK}^{(135)}$. Preliminary evidence suggests that FOP labels may also promote healthier food purchasing behaviours, although additional research is needed $^{(7,15)}$.

Evidence is mixed with respect to the level of detail or complexity of information favoured by consumers. More detailed information was favoured by some consumers $^{(76,79,131)}$, especially non-label users ${ }^{(17)}$, whereas frequent users preferred less detail ${ }^{(17)}$. Simplified labels have been shown to promote more accurate nutrition judgements of unhealthy products ${ }^{(74,84,119)}$ and improved performance on diet-related tasks ${ }^{(121,131)}$, even when daily reference values were added ${ }^{(121)}$. The use of reference information, such as per cent daily value, is often welcomed by consumers $^{(122,133,134)}$; however, many struggle to apply the quantitative values $^{(7,124,138)}$. Labels presenting information in two columns side-by-side have also been shown to reduce food consumption by non-dieters when compared with a version presenting information as a single, longer column $^{(139)}$. Consumers have also expressed a desire for nutrient information listed in the context of a healthy $\operatorname{diet}^{(93,131)}$; larger, more legible print ${ }^{(37,130)}$; simpler terms ${ }^{(76)}$; explanations of terms or nutrients ${ }^{(37,93)}$; the use of colour and a consistent appearance across nutrition labels ${ }^{(93)}$.

\section{Types of nutrition information sought by consumers}

Consumers tend to look more closely at nutrients they wish to avoid $^{(93)}$. To this end, the nutrients most commonly sought were fat ${ }^{(26,28,37,42,49,53,73,79,85,97,108,115,118)}$, energy content ${ }^{(28,37,53,79,97,118)}$, protein ${ }^{(49,79,97,118)}$, cholesterol $^{(28,97)}$, carbohydrates ${ }^{(42,118)}$, vitamins and minerals $^{(97,118)}$, types of fat ${ }^{(42,97)}$, serving size ${ }^{(85)}$, additives ${ }^{(42,73)}$ and $\mathrm{Na}$ information ${ }^{(42,97,118)}$. Low-fat dieters were more likely to look at fat information ${ }^{(42,53,98)}$, and younger ${ }^{(67,73)}$ female participants were more likely to look at energy than men ${ }^{(59,67)}$. Cholesterol was most often looked at by older $^{(50,67,98)}$, suburban participants who believed in a diet-disease relationship ${ }^{(98)}$ and had high cholesterol ${ }^{(53)}$, and less often looked at by white, well-educated individuals with low cholesterol intake ${ }^{(98)}$. Those with experience reading labels were more likely to use carbohydrates and fibre information ${ }^{(59)}$, and younger individuals were more likely to use vitamin and mineral information ${ }^{(67)}$.

Similar to the general population, adolescents were most likely to seek fat and energy information ${ }^{(87)}$. A range of studies have also examined information sought by a range of other sub-populations, including low-income women ${ }^{(38,41)}$, Latino populations ${ }^{(72)}$ and diabetes patients ${ }^{(106)}$.

\section{The impact of nutrition labels on diet}

Observational studies have consistently found an association between use of nutrition labels and healthier $\operatorname{diets}^{(70-72,82,103,140,141)}$. Several studies have reported an association between label use and lower fat consumption $^{(70-72,82,140,141)}$. Label users are also more likely to eat healthier varieties of foods ${ }^{(140)}$, and to have reduced $\mathrm{Na}^{(72,103)}$, cholesterol ${ }^{(63,72)}$ and energy intakes, coupled with increased fibre ${ }^{(72,142)}, \mathrm{Fe}^{(143)}$ and vitamin $\mathrm{C}$ intakes ${ }^{(70)}$. Cross-sectional associations between label use and healthier diets are also related to socio-economic status ${ }^{(142)}$, education $^{(71,82)}$ age $^{(71,72)}$ gender $^{(36,72)}$ and ethnicity/race ${ }^{(71,72)}$.

Three longitudinal studies in the USA have evaluated the implementation of new nutrition labels on dietary patterns. In the USA, the 1990 Nutrition Labeling and Education Act came into effect in 1994 and required nutrition labels on all pre-packaged foods. A study comparing nationally representative surveys of consumers in 1989 and 1995 found that frequent label users in 1995 had a significantly greater probability of consuming a low-fat diet than both non-label users in 1995 and frequent label users in $1989^{(74)}$. In addition, fat intake among lesseducated respondents decreased significantly during the 'pre-post' study period ${ }^{(74)}$. A second study found that BMI of nutrition label users fell significantly following implementation of the Act, with the greatest change among those with the highest BMI score ${ }^{(104)}$. In addition, low-fat and low-Na food purchases increased significantly following the impact of new labels, although the same effect was not observed for low-energy choices, or healthy nutrients such as vitamins and minerals ${ }^{(116)}$

Evidence from five experimental studies is generally consistent with cross-sectional and longitudinal findings. Two experiments compared consumption of low-fat with energy-dense foods by randomizing participants to either a blind or information condition ${ }^{(144,145)}$. Both studies found that, although participants tended to consume greater amounts of reduced-energy food in terms of food weight, total energy intake was significantly lower among those who consumed reduced-energy food ${ }^{(144,145)}$. Only one study showed this effect on daily energy consumption, as opposed to short-term intake during the study ${ }^{(145)}$. Participants who received nutrition information consumed more of the low-energy version of the food $^{(144)}$. A third experiment found no differences in participants' satiety after consuming fat-free compared with regular potato chips, irrespective of the provision of information $^{(146)}$. Finally, providing nutrition information also increased healthier purchase intentions and accurate perceptions of nutrient content ${ }^{(147)}$.

\section{Discussion}

Research conducted to date indicates that nutrition labels on pre-packaged foods are among the most prominent 
sources of nutrition information. Evidence also suggests that consumers perceive nutrition labels to be a highly credible source of information, and many consumers report using nutrition labels to guide their selection of food products.

The use of nutrition labels varies considerably across population subgroups. Use is particularly high among individuals with health conditions and special dietary requirements - those with the greatest need for nutritional information. However, label use is notably lower among children, adolescents and older adults. More research targeting these populations is needed, given their increased prevalence of obesity ${ }^{(1,148)}$, nutrient deficiencies $^{(149)}$ and chronic disease ${ }^{(149-153)}$. Individuals with lower socio-economic status are also less likely to use nutrition labels, which is particularly problematic given that low socio-economic status is associated with an increased risk of being overweight and obese ${ }^{(154)}$.

The evidence in this review shows a consistent link between the use of nutrition labels and healthier diets. The causal nature of this association is likely bidirectional: nutrition labels may promote healthier eating, whereas individuals with healthier diets are more likely to seek out nutritional labels in the first place. However, there is sufficient evidence from a range of study designs to conclude that providing nutrition information on packages has a positive impact on diet. In countries such as the USA, government agencies and non-government organizations have estimated the impact of mandatory nutrition labelling to be in the range of billions of dollars ${ }^{(104)}$, although the magnitude of benefit and the extent to which it varies across different types of nutrition labels and population subgroups cannot be estimated with any precision from the existing evidence base.

Research to date also highlights the need to balance the complexity of information presented on labels with consumers' ability to process this information in a quick and meaningful manner. Nutrition labels that require calculations with respect to nutrient amounts and serving sizes are confusing to many consumers, particularly those with lower education and literacy skills ${ }^{(96)}$. Educational interventions aimed at improving the understanding of nutrition labels have shown promise and a broader application of these interventions may provide one potential solution ${ }^{(92,155)}$; however, the evidence highlights the need to improve the ways in which nutrition information is presented to consumers on food packages.

Future research should examine the effectiveness of using symbols, images and different graphical layouts to a greater extent. Indeed, there is growing evidence regarding the consumer-friendly nature symbols used by the industry, as well as the greater impact of FOP labels, compared with labels on the side or back of packages. These formats may be more consumer-friendly in part because nutrition information is more accessible and in part because of a widespread desire for more 'prescriptive' information that identifies 'healthier' food from lesshealthy options. Indeed, an expert panel commissioned by the UK Food Standards Agency recently concluded that FOP formats are effective and the strongest FOP label is one that combines the use of words 'high, medium and low', traffic light colours and percentage of Guideline Daily Amount, in addition to levels of nutrients in a portion of the product ${ }^{(156)}$.

More generally, there is increasing evidence that labelling regulations need to take the entire package into consideration to maximize their effectiveness. Industry 'health claims' are regulated to different extents across jurisdictions and the use of FOP symbols, which imply healthier alternatives, is largely unregulated. Ideally, consumers would use nutrition labels to help interpret health claims; however, in practice, many consumers rely solely on health claims ${ }^{(108)}$. Indeed, there have been mixed reports as to whether consumers can determine whether claims are truthful ${ }^{(56,114,120,157)}$.

\section{Limitations}

This review is subject to several limitations. First, it is possible that relevant articles were not included in the review, given the rapidly evolving evidence base. Attempts were made to minimize this limitation by using a comprehensive searching strategy and a systematic selection process using two independent reviewers and inclusion criteria. Second, the articles included in this review were disproportionately from high-income Western countries, and from North America in particular. Therefore, it is unclear as to what extent the findings in this review apply to jurisdictions with different labelling regulations and in much different cultural and geographical contexts. Additional research on the impact of nutrition labels in low- and middle-income countries should be considered a priority. Even among the Western countries included in this review, there are important differences in labelling regulations that were not fully examined. The diversity in study protocols, measures and samples also presents challenges in terms of comparing studies. We have tried to note major differences wherever possible; however, it is likely that methodological differences between studies account for at least some of the variability in the findings. Finally, much of the evidence on the impact of nutrition labels is based on self-report data, which may over-report the use of nutrition labels, meaning that other factors, such as greater awareness of the link between nutrition and chronic disease, may be responsible for population-level changes over time that have been attributed to nutrition labels.

\section{Conclusions}

Population-level interventions and changes to the food environment are necessary to halt the rising health and economic burden from obesity. The evidence to date 
indicates that nutrition labels on pre-packaged foods are a cost-effective population-level intervention with considerable reach. In order to capitalize upon the potential of nutrition labels, governments will need to explore new formats and different types of information content to ensure that nutrition information is accessible and understandable. A number of jurisdictions are in the process of developing new formats and revising labelling standards, such as the European Union ${ }^{(158)}$. There is an immediate need for evidence to inform these regulatory developments. Regulators should also consider expanding the scope of mandatory nutrition labelling. In the vast majority of jurisdictions, nutrition labelling regulations are limited to pre-packaged food products and do not apply to foods served in restaurants or fast-food outlets, which account for a significant proportion of dietary intake in many high-income countries ${ }^{(159,160)}$. Mandatory display of nutrition information on menus and menu boards of food outlets may be a promising means of increasing the impact of nutrition labelling regulations ${ }^{(161)}$ and harmonizing nutrient information across information channels.

\section{Acknowledgements}

Funding support for this manuscript was provided by the Propel Centre for Population Health Impact, with funds from the Canadian Cancer Society. The authors have no conflict of interest to declare. Each of the authors made a direct contribution to this manuscript. D.H. conceived of the study; J.D. and S.C. conducted the article searching; and J.D., S.C. and D.H. co-authored the manuscript. The authors acknowledge the assistance of Priya Kekree and Samantha Daniel in preparing the manuscript for publication.

\section{References}

1. Shields M (2006) Overweight and obesity among children and youth. Health Rep 17, 27-42.

2. World Health Organization (2003) WHO: Obesity and Overweight. What Are Obesity and Overweight? WHO Fact Sheet no. 311. Geneva: WHO.

3. Luo W, Morrison H, de Groh M et al. (2007) The burden of adult obesity in Canada. Chronic Dis Can 27, 135-144.

4. World Health Organization (2003) Cancer: Diet and Physical Activity's Impact. http://www.who.int/dietphysicalactivity/ publications/facts/cancer/en/ (accessed December 2010).

5. Public Health Agency of Canada (2006) Healthy Aging in Canada: A New Vision, A Vital Investment, From Evidence to Action - A Background Paper. http://www.phac-aspc.gc.ca/ seniors-aines/publications/pro/healthy-sante/haging_newvision/ vison-rpt/index-eng.ph (accessed December 2010).

6. Cowburn G \& Stockley L (2005) Consumer understanding and use of nutrition labelling: a systematic review. Public Health Nutr 8, 21-28.

7. Feunekes GI, Gortemaker IA, Willems AA et al. (2008) Front-of-pack nutrition labelling: testing effectiveness of different nutrition labelling formats front-of-pack in four European countries. Appetite 50, 57-70.

8. US Food and Drug Administration (1994) Guide to Nutrition Labelling and Education Act (NLEA) Requirements. Silver
Spring, MD: Division of Field Investigations, Office of Regional Operations, Office of Regulatory Affairs, US Food \& Drug Administration.

9. Health Canada (2010) Nutritional labelling. http://www.hcsc.gc.ca/fn-an/label-etiquet/nutrition/index-eng.php (accessed December 2010).

10. Government of Canada (2002) Food and Drugs Act. Regulations Amending the Food and Drug Regulations (Nutrition Labelling, Nutrient Content Claims and Health Claims). Canada Gazette Part II 137(1):Registration SOR/ 2003-11 12.

11. The Council of European Communities (1990) Council directive 90/496/EEC on nutrition labelling for foodstuffs of 24 September 1990. Off J Eur Commun L276, 40-44.

12. Geiger CJ, Wyse BW, Parent CR et al. (1991) Review of nutrition labelling formats. J Am Diet Assoc 91, 808-812.

13. Baltas G (2001) Nutrition labelling: issues and policies. Eur J Mark 35, 708-721.

14. Drichoutis A (2006) 103 Consumers' use of nutritional labels: a review of research studies and issues. Acad Mark Sci Rev 9 , 93-118.

15. Grunert K (2007) A review of European research on consumer response to nutrition information on food labels. J Public Health 15, 385-389.

16. Mhurchu CN \& Gorton D (2007) Nutrition labels and claims in New Zealand and Australia: a review of use and understanding. Aust N Z J Public Health 31, 105-112.

17. Klopp P \& MacDonald M (1981) Nutrition labels: an exploratory study of consumer reasons for nonuse. J Consum Aff 15, 301-316.

18. US Department of Health and Human Services, Centers for Disease Control and Prevention (2001) Healthy People 2000 Final Review. Library of Congress Catalog Card no. 76-641496. Hyattsville, MD: Public Health Service.

19. Kessler H \& Wunderlich SM (1999) Relationship between use of food labels and nutrition knowledge of people with diabetes. Diabetes Educ 25, 549-559.

20. Coulson NS (2000) An application of the stages of change model to consumer use of food labels. Br Food J 102, 661-668.

21. Dooley DA, Novotny R \& Britten P (1998) Integrating research into the undergraduate nutrition curriculum: Improving shoppers' awareness and understanding of nutrition facts labels. J Nutr Educ 30, 225-231.

22. Lindhorst K, Corby L, Roberts S et al. (2007) Rural consumers' attitudes: towards nutrition labelling. Can J Diet Pract Res 68, 146-149.

23. Perez-Escamilla R, Himmelgreen D, Bonello $\mathrm{H}$ et al. (2001) Nutrition knowledge, attitudes, and behaviors among Latinos in the USA: influence of language. Ecol Food Nutr 40, 321-345.

24. Piche LA \& Garcia AC (2001) Factors influencing foodbuying practices of grocery shoppers in London, Ontario. Can J Diet Pract Res 62, 199-202.

25. Bender MM \& Derby BM (1992) Prevalence of reading nutrition and ingredient information on food labels among adult Americans: 1982-1988. J Nutr Educ 24, 292-297.

26. Crawford D \& Baghurst KI (1990) Community views on food labelling. Food Aust 42, 231-233.

27. Blitstein JL \& Evans WD (2006) Use of nutrition facts panels among adults who make household food purchasing decisions. J Nutr Educ Behav 38, 360-364.

28. Kristal AR, Levy L, Patterson RE et al. (1998) Trends in food label use associated with new nutrition labelling regulations. Am J Public Health 88, 1212-1215.

29. Szykman LR, Bloom PN \& Levy AS (1997) A proposed model of the use of package claims and nutrition labels. J Public Policy Mark 16, 228-241. 
30. Satia JA, Galanko JA \& Neuhouser ML (2005) Food nutrition label use is associated with demographic, behavioral, and psychosocial factors and dietary intake among African Americans in North Carolina. J Am Diet Assoc 105, 392-402.

31. Shine A, O'Reilly S \& O'Sullivan K (1997) Consumer attitudes to nutrition labelling. Br Food J 99, 283-289.

32. Reid DJ, Conrad SA \& Hendricks SM (1996) Tracking nutrition trends, 1989-1994: an update on Canadians' attitudes, knowledge and reported actions. Can J Public Health 87, 113-118.

33. Rasberry CN, Chaney BH, Housman JM et al. (2007) Determinants of nutrition label use among college students. Am J Health Educ 38, 76-82.

34. Byrd-Bredbenner C, Alfieri L, Wong A et al. (2001) The inherent educational qualities of nutrition labels. Fam Consum Sci Res J 29, 265-280.

35. Jensen K, Adams L, Hollis S et al. (1996) The new nutrition labels: a study of consumers' use for dairy products. J Food Distrib Res 27, 49-57.

36. Huang TTK, Kaur H, McCarter KS et al. (2004) Reading nutrition labels and fat consumption in adolescents. J Adolesc Health 35, 399-401.

37. Mannell A, Brevard P, Nayga R Jr et al. (2006) French consumers' use of nutrition labels. Nutr Food Sci 36, 159-168.

38. Michel P, Korslund M, Finan A et al. (1994) Food label reading habits of WIC clients. J Nutr Educ 26, 146-148.

39. Hyman DJ, Simons-Morton DG, Ho K et al. (1993) Cholesterol-related knowledge, attitudes, and behaviors in a low-income, urban patient population. Am J Prev Med 9, 282-289.

40. Kessler H \& Wunderlich SM (1999) Relationship between use of food labels and nutrition knowledge of people with diabetes. Diabetes Educ 25, 549-559.

41. McArthur L, Chamberlain V \& Howard AB (2001) Behaviors, attitudes, and knowledge of low-income consumers regarding nutrition labels. J Health Care Poor Underserved 12, 415-428.

42. Wandel M (1997) Food labelling from a consumer perspective. Br Food J 99, 212-219.

43. Briley ME, Owens MS, Gillham MB et al. (1990) Sources of nutrition information for rural and urban elderly adults. J Am Diet Assoc 90, 986-987.

44. Worsley A (2003) Consumers' personal values and sources of nutrition information. Ecol Food Nutr 42, 129-151.

45. Zarkin GA \& Anderson DW (1992) Consumer and producer responses to nutrition label changes. Am J Agric Econ 74, 1202-1207.

46. Peters-Texeira A \& Badrie N (2005) Consumers' perception of food packaging in Trinidad, West Indies and its related impact on food choices. Int J Consum Stud 29, 508-514.

47. Loureiro ML, Gracia A \& Nayga RM Jr (2006) Do consumers value nutritional labels? Eur Rev Agric Econ 33, 249-268.

48. James D (2004) Factors influencing food choices, dietary intake, and nutrition-related attitudes among African Americans: application of a culturally sensitive model. Ethn Health 9, 349-367.

49. Heimbach JT \& Orwin RG (1984) Public perceptions of sodium labelling. J Am Diet Assoc 84, 1217-1219.

50. Elbon SM, Johnson MA \& Fischer JG (2000) Demographic factors, nutrition knowledge, and health-seeking behaviors influence nutrition label reading behaviors among older American adults. J Nutr Elder 19, 31-48.

51. Haldeman L, Pérez-Escamilla R, Ferris AM et al. (2000) Development of a color-coded bilingual food label for low-literacy Latino caretakers. J Nutr Educ 32, 152-160.

52. Rothman RL, Housam R, Weiss H et al. (2006) Patient understanding of food labels the role of literacy and numeracy. Am J Prev Med 31, 391-398.
53. Kreuter MW, Brennan LK, Scharff DP et al. (1997) Do nutrition label readers eat healthier diets? Behavioral correlates of adults' use of food labels. Am J Prev Med 13, 277-283.

54. Hawthorne KM, Moreland K, Griffin IJ et al. (2006) An educational program enhances food label understanding of young adolescents. J Am Diet Assoc 106, 913-916.

55. Alfieri L \& Byrd-Bredbenner C (2000) Assessing the performance of women on nutrition labelling tasks. $A m$ J Health Stud 16, 113-123.

56. Byrd-Bredbenner C (2000) The ability of college women aged 17 to 25 to perform tasks using nutrition facts labels. Int Electron J Health Educ 3, 97-106.

57. Byrd-Bredbenner C, Wong A \& Cottee P (2000) Consumer understanding of US and EU nutrition labels. $\mathrm{Br}$ Food $\mathrm{J}$ 102, 615-629.

58. Mohr KG, Wyse BW \& Gaurth Hansen R (1980) Aiding consumer nutrition decisions: comparison of a graphical nutrient density labelling format with the current food labelling system. Fam Consum Sci Res J 8, 162-172.

59. Marietta AB, Welshimer KJ \& Long Anderson S (1999) Knowledge, attitudes, and behaviors of college students regarding the 1990 nutrition labelling education act food labels. J Am Diet Assoc 99, 445-449.

60. Smith SC, Taylor JG \& Stephen AM (2007) Use of food labels and beliefs about diet-disease relationships among university students. Public Health Nutr 3, 175-182.

61. Signal L, Lanumata T, Robinson JA et al. (2008) Perceptions of New Zealand nutrition labels by Māori, Pacific and lowincome shoppers. Public Health Nutr 11, 706-713.

62. Wang G, Fletcher SM \& Carley DH (1995) Consumer utilization of food labelling as a source of nutrition information. J Consum Aff 29, 368-380.

63. Guthrie JF, Fox JJ, Cleveland LE et al. (1995) Who uses nutrition labelling, and what effects does label use have on diet quality? J Nutr Educ 27, 163-172.

64. Gorton D, Ni Mhurchu C, Chen M et al. (2008) Nutrition labels: a survey of use, understanding and preferences among ethnically diverse shoppers in New Zealand. Public Health Nutr 12, 1359-1365.

65. Crane NT, Hubbard VS \& Lewis CJ (1999) American diets and year 2000 goals. In America's Eating Habits: Changes and Consequences. Agriculture Information Bulletin no. 750, pp. 111-133 [E Frazao, editor]. Washington, DC: Economic Research Service, US Department of Agriculture.

66. Higginson CS, Rayner MJ, Draper S et al. (2002) The nutrition label - which information is looked at? Nutr Food Sci 32, 92-99.

67. Drichoutis AC, Lazaridis P \& Nayga RM Jr (2005) Who is looking for nutritional food labels? Wer sucht nach nahrwertangaben auf lebensmitteln?: Mais qui donc s' occupe du contenu nutritionnel sur les etiquettes? Eurochoices 4, 18-23.

68. Lin BH \& Yen ST (2008) Consumer knowledge, food label use and grain consumption in the US. Appl Econ 40, 437-448.

69. Drichoutis AC, Lazaridis P, Nayga RM et al. (2008) A theoretical and empirical investigation of nutritional label use. Eur J Health Econ 9, 293-304.

70. Neuhouser ML, Kristal AR \& Patterson RE (1999) Use of food nutrition labels is associated with lower fat intake. J Am Diet Assoc 99, 45-53.

71. Kim S \& Douthitt RA (2004) The role of dietary information in women's whole milk and low-fat milk intakes. Int J Consum Stud 28, 245-254.

72. Kim S, Nayga RM Jr \& Capps O (1999) The effect of new food labelling on nutrient intakes: an endogenous switching regression analysis. Selected paper presented at the Annual Meeting of the American Agricultural Economics Association, Nashville TN, USA, 8-11 August 1999. 
73. Wandel M \& Bugge A (1996) Nutrition information in the market: food labelling as an aid to the consumer. Int $J$ Consum Stud 20, 215-228.

74. Finke MS (2000) Did the Nutrition Labelling and Education Act Affect Food Choices in the United States? The American Consumer and the Changing Structure of the Food System Conference. Arlington, VA: Economic Research Service, US Department of Agriculture.

75. Byrd-Bredbenner C, Wong A \& Cottee P (2000) Consumer understanding of US and EU nutrition labels. $\mathrm{Br}$ Food $\mathrm{J}$ 102, 615-629.

76. Abbott R (1997) Food and nutrition information: a study of sources, uses and understanding. Br Food J 99, 43-49.

77. Levy L, Patterson RE, Kirstal AR et al. (2000) How well do consumers understand percentage daily value of food labels? Am J Health Promot 14, 157-160.

78. Worsley A \& Lea E (2003) Consumers' personal values and sources of nutrition information. Ecol Food Nutr 42, 129-151.

79. Hager MH, Geiger C, Hill LJ et al. (2009) Usefulness of nutrition facts label for persons with chronic kidney disease. J Ren Nutr 19, 204-210.

80. Canadian Council of Food and Nutrition (2006) Tracking Nutrition Trends VI. Woodbridge, Ontario, Canada: CCFN.

81. Daly PA (1976) The response of consumers to nutrition labelling. J Consum Aff 10, 170-178.

82. Kim SY, Nayga RM Jr \& Capps O (2001) Food label use, selfselectivity, and diet quality. J Consum Aff 35, 346-363.

83. Petrovici DA \& Ritson C (2006) Factors influencing consumer dietary health preventative behaviours. BMC Public Health 6, 222.

84. Burton S \& Andrews JC (1996) Age, product nutrition, and label format effects on consumer perceptions and product evaluations. J Consum Aff 30, 68-89.

85. Misra R (2007) Knowledge, attitudes, and label use among college students. J Am Diet Assoc 107, 2130-2134.

86. Drichoutis AC, Lazaridis P \& Nayga RM Jr (2005) Nutrition knowledge and consumer use of nutritional food labels. Eur Rev Agric Econ 32, 93-118.

87. McCullum C \& Achterberg CL (1997) Food shopping and label use behavior among high school-aged adolescents. Adolescence 32, issue 125, 181-197.

88. Long JAD, Armstrong ML, Amos E et al. (2006) Pilot using world wide web to prevent diabetes in adolescents. Clin Nurs Res 15, 67-79.

89. Abood DA, Black DR \& Coster DC (2008) Evaluation of a school-based teen obesity prevention minimal intervention. J Nutr Educ Behav 40, 168-174.

90. James DCS, Rienzo BA \& Frazee C (1997) Using focus groups to develop a nutrition education video for high school students. J Sch Health 67, 376-379.

91. Lytle LA, Eldridge A, Kotz K et al. (1997) Children's interpretation of nutrition messages. J Nutr Educ 29, 128-136.

92. Jay M, Adams J, Herring SJ et al. (2009) A randomized trial of a brief multimedia intervention to improve comprehension of food labels. Prev Med 48, 25-31.

93. Shine A, O'Reilly S \& O'Sullivan K (1997) Consumer use of nutrition labels. Br Food J 99, 290-296.

94. Nayga RM Jr (2000) Nutrition knowledge, gender, and food label use. J Consum Aff 34, 97-112.

95. Burton S, Garretson JA \& Velliquette AM (1999) Implications of accurate usage of nutrition facts panel information for food product evaluations and purchase intentions. J Acad Mark Sci 27, 470-480.

96. Nayga RM Jr, Lipinski D \& Savur N (1998) Consumers' use of nutritional labels while food shopping and at home. J Consum Aff 32, 106-120.

97. Hess S, Yanes M, Jourdan P et al. (2005) Trans fat knowledge is related to education level and nutrition facts label use in health-conscious adults. Top Clin Nutr 20, 109-117.
98. Lin CTJ, Lee JY \& Yen ST (2004) Do dietary intakes affect search for nutrient information on food labels? Soc Sci Med 59, 1955-1967.

99. Ward RW \& Jauregui C (2006) Do consumers really use food labels? Presented at 2006 Annual Meeting of the American Agricultural Economics Association, Long Beach, CA, USA, 23-26 July.

100. Gans KM, Burkholder GJ, Risica PM et al. (2003) Baseline fat-related dietary behaviors of white, Hispanic, and black participants in a cholesterol screening and education project in new England. I Am Diet Assoc 103, 699-706.

101. Krystallis A \& Ness M (2004) Motivational and cognitive structures of Greek consumers in the purchase of quality food products. I Int Consum Mark 16, 7-36.

102. Higginson CS, Kirk TR, Rayner MJ et al. (2002) How do consumers use nutrition label information? Nutr Food Sci 32, 145-152.

103. Fitzgerald N, Damio G, Segura-Pérez S et al. (2008) Nutrition knowledge, food label use, and food intake patterns among Latinas with and without type 2 diabetes. J Am Diet Assoc 108, 960-967.

104. Variyam JN \& Cawley J (2006) Nutrition Labels and Obesity. NBER Working Paper no. 11956. Cambridge, MA: National Bureau of Economic Research.

105. Miller CK, Jensen GL \& Achterberg CL (1999) Evaluation of a food label nutrition intervention for women with type 2 diabetes mellitus. I Am Diet Assoc 99, 323-328.

106. Miller CK, Probart CK \& Achterberg CL (1997) Knowledge and misconceptions about the food label among women with non-insulin-dependent diabetes mellitus. Diabetes Educ 23, 425-432.

107. Silayoi P \& Speece M (2004) Packaging and purchase decisions. Br Food J 106, 607-628.

108. Reid DJ \& Hendricks S (1993) Consumer awareness of nutrition information on food package labels. J Can Diet Assoc 54, 127-131.

109. Aikman SN, Min KE \& Graham D (2006) Food attitudes, eating behavior, and the information underlying food attitudes. Appetite 47, 111-114.

110. Byrd-Bredbenner C \& Kiefer L (2001) The ability of elderly women to perform nutrition facts label tasks and judge nutrient content claims. I Nutr Elder 20, 29-46.

111. Miller C \& Brown J (1999) Knowledge and use of the food label among senior women in the management of type 2 diabetes mellitus. J Nutr Health Aging 3, 152-157.

112. Tessaro I, Rye S, Parker L et al. (2007) Effectiveness of a nutrition intervention with rural low-income women. Am J Health Behav 31, 35-43.

113. Sullivan AD (2003) Determining how low-income food shoppers perceive, understand, and use food labels. Can J Diet Pract Res 64, 25-27.

114. Keller SB, Landry M, Olson J et al. (1997) The effects of nutrition package claims, nutrition facts panels, and motivation to process nutrition information on consumer product evaluations. I Public Pol Mark 16, 256-269.

115. Garretson JA \& Burton S (2000) Effects of nutrition facts panel values, nutrition claims, and health claims on consumer attitudes, perceptions of disease-related risks, and trust. J Public Pol Mark 19, 213-227.

116. Balasubramanian SK \& Cole C (2002) Consumers' search and use of nutrition information: the challenge and promise of the nutrition labelling and education act. JMark 66, 112-127.

117. Kozup JC, Creyer EH \& Burton S (2003) Making healthful food choices: the influence of health claims and nutrition information on consumers' evaluations of packaged food products and restaurant menu items. J Mark 67, 19-34.

118. Heimbach JT \& Stokes RC (1982) Nutrition labelling and public health: survey of American Institute of Nutrition members, food industry, and consumers. Am J Clin Nutr 36, 700-708. 
119. Goldberg JH, Probart CK \& Zak RE (1999) Visual search of food nutrition labels. Hum Factors 41, 425-437.

120. Levy AS \& Fein SB (1998) Consumers' ability to perform tasks using nutrition labels. J Nutr Educ 30, 210-217.

121. Levy A, Fein SB \& Schucker RE (1992) More effective nutrition label formats are not necessarily preferred. $J$ Am Diet Assoc 92, 1230-1234.

122. Burton S, Biswas A \& Netemeyer R (1994) Effects of alternative nutrition label formats and nutrition reference information on consumer perceptions, comprehension, and product evaluations. J Public Pol Mark 13, 36-47.

123. Howlett E, Burton S \& Kozup J (2008) How modification of the nutrition facts panel influences consumers at risk for heart disease: the case of trans fat. J Public Pol Mark 27, 83-97.

124. The Strategic Counsel (2010) Focus testing of creatives for the nutrition facts education initiative. Prepared for Health Canada. http://epe.lac-bac.gc.ca/100/200/301/pwgsc-tpsgc/ por-ef/health/2010/075-09/report.pdf (accessed September 2010).

125. Block LG \& Peracchio LA (2006) The calcium quandary: how consumers use nutrition labels. J Public Pol Mark 25, 188-196.

126. Pelletier AL, Chang WW, Delzell JE et al. (2004) Patients' understanding and use of snack food package nutrition labels. I Am Board Fam Med 17, 319-323.

127. Miller CK, Edwards L, Kissling G et al. (2002) Evaluation of a theory-based nutrition intervention for older adults with diabetes mellitus. J Am Diet Assoc 102, 1069-1081.

128. Li F, Miniard PW \& Barone MJ (2000) The facilitating influence of consumer knowledge on the effectiveness of daily value reference information. J Acad Mark Sci $\mathbf{2 8}$, 425-436.

129. Marino CJ \& Mahan RP (2005) Configural displays can improve nutrition-related decisions: An application of the proximity compatibility principle. J Hum Factors Ergon Soc 47, 121-130.

130. Lewis CJ \& Yetley EA (1992) Focus group sessions on formats of nutrition labels. J Am Diet Assoc 92, 62-66.

131. Geiger CJ, Wyse BW, Parent CR et al. (1991) Nutrition labels in bar graph format deemed most useful for consumer purchase decisions using adaptive conjoint analysis. J Am Diet Assoc 91, 800-807.

132. Levy AS, Fein SB \& Schucker RE (1996) Performance characteristics of seven nutrition label formats. $J$ Public Pol Mark 15, 1-15.

133. Jones G \& Richardson M (2007) An objective examination of consumer perception of nutrition information based on healthiness ratings and eye movements. Public Health Nutr 10, 238-244.

134. Kelly B, Hughes C, Chapman K et al. (2009) Consumer testing of the acceptability and effectiveness of front-ofpack-food labelling systems for the Australian grocery market. Health Promot 24, 120-129.

135. van Kleef E, van Trijp H, Paeps F et al. (2008) Consumer preferences for front-of-pack calories labelling. Public Health Nutr 11, 203-213.

136. Borgmeier I \& Westenhoefer J (2009) Impact of different food label formats on healthiness evaluation and food choice of consumers: a randomized-controlled study. BMC Public Health 12, 184.

137. Wansink B (2003) How do front and back package labels influence beliefs about health claims? J Consum Aff 37, 305-316.

138. Barone MJ, Rose RL, Manning KC et al. (1996) Another look at the impact of reference information on consumer impressions of nutrition information. J Public Pol Mark 15, 55-62.

139. Antonuk B \& Block LG (2006) The effect of single serving versus entire package nutritional information on consumption norms and actual consumption of a snack food. J Nutr Educ Behav 38, 365-370.

140. Nayga RM Jr (1999) Retail health marketing: evaluating consumers' choice for healthier foods. Health Mark $Q \mathbf{1 6}$, 53-65.

141. Kristal AR, Hedderson MM, Patterson RE et al. (2001) Predictors of self-initiated, healthful dietary change. $J \mathrm{Am}$ Diet Assoc 101, 762-766.

142. Variyam JN (2008) Do nutrition labels improve dietary outcomes? Health Econ 17, 695-708.

143. Variyam JN (2008) Do nutrition labels improve dietary outcomes? Health Econ 17, 695-708.

144. Miller DL, Castellanos VH, Shide DJ et al. (1998) Effect of fat-free potato chips with and without nutrition labels on fat and energy intakes. Am J Clin Nutr 68, 282-290.

145. Kral T, Roe L \& Rolls B (2002) Does nutrition information about the energy density of meals affect food intake in normal-weight women? Appetite 39, 137-145.

146. Miller DL, Bell EA, Pelkman CL et al. (2000) Effects of dietary fat, nutrition labels, and repeated consumption on sensory-specific satiety. Physiol Behav 71, 153-158.

147. Baixauli R, Salvador A, Hough G et al. (2008) How information about fibre (traditional and resistant starch) influences consumer acceptance of muffins. Food Qual Prefer 19, 628-635.

148. Federal Interagency Forum on Aging-Related Statistics (2008) Older Americans 2008: Key Indicators of WellBeing. Washington, DC: U.S. Government Printing Office.

149. Ferrini AF \& Ferrini RL (2000) Nutrition. In Health in the Later Years, 3rd ed., p. 152. Boston, MA: McGraw-Hill.

150. Freedman DS, Dietz WH, Srinivasan SR et al. (1999) The relation of overweight to cardiovascular risk factors among children and adolescents: The Bogalusa Heart Study. Pediatrics 103, 1175-1182.

151. Pinhas-Hamiel O, Dolan LM, Daniels SR et al. (1996) Increased incidence of non-insulin-dependent diabetes mellitus among adolescents. J Pediatr 128, 608-615.

152. Srinivasan SR, Myers L \& Berenson GS (2002) Predictability of childhood adiposity and insulin for developing insulin resistance syndrome (syndrome $\mathrm{X}$ ) in young adulthood. Diabetes 51, 204-209.

153. Ferrini AF \& Ferrini RL (2000) Chronic disease. In Health in the Later Years, 3rd ed., p. 239. Boston, MA: McGraw-Hill.

154. Mackenbach JP (2005) Genetics and health inequalities: hypotheses and controversies. I Epidemiol Commun Health 59, 268-273.

155. Carson JAS \& Hedl JJ (1998) Smart shoppers tours: outcome evaluation. J Nutr Educ 30, 323-331.

156. Malam S, Cleeg S, Kirwan S, et al. (2009) Comprehension and use of UK nutrition signpost labelling schemes. Prepared for the UK Food Standards Agency. http:// www.food.gov.uk/news/newsarchive/2009/may/pmp (accessed June 2010).

157. Reid DJ \& Hendricks SM (1994) Consumer understanding and use of fat and cholesterol information on food labels. Can J Public Health 85, 334-337.

158. UK Food Standards Agency (2008) Proposed regulation on food information for consumers. http://www.food.gov.uk/ foodlabelling/ull/labellingproposals/ (accessed March 2010).

159. Guthrie JF, Lin BH \& Frazao E (2002) Role of food prepared away from home in the American diet, 1977-78 versus 1994-96: changes and consequences. J Nutr Educ Behav 34, 140-150.

160. US Department of Agriculture, Economic Research Services (2008) Food CPI, Prices and Expenditures: Food Away from Home. Washington, DC: USDA/ERS.

161. Berman M \& Lavizzo-Mourey R (2008) Obesity prevention in the information age: caloric information at the point of purchase. JAMA 300, 433-435. 